\title{
Depression, Obesity, Eating Behavior, and Physical Activity
}

\author{
Kristin L. Schneider, ${ }^{1}$ Austin S. Baldwin, ${ }^{2}$ Devin M. Mann, ${ }^{3}$ and Norbert Schmitz ${ }^{4}$ \\ ${ }^{1}$ Department of Psychology, Rosalind Franklin University of Medicine and Science, North Chicago, IL 60064, USA \\ ${ }^{2}$ Department of Psychology, Southern Methodist University, Dallas, TX 75275-0442, USA \\ ${ }^{3}$ Department of Medicine, Boston University, Boston, MA 02118, USA \\ ${ }^{4}$ Department of Psychiatry, Faculty of Medicine, McGill University, Montreal, QC, Canada H4H 1 R3
}

Correspondence should be addressed to Kristin L.Schneider, kristin.schneider@rosalindfranklin.edu

Received 29 August 2012; Accepted 29 August 2012

Copyright ( $) 2012$ Kristin L. Schneider et al. This is an open access article distributed under the Creative Commons Attribution License, which permits unrestricted use, distribution, and reproduction in any medium, provided the original work is properly cited.

\section{Introduction to Special Issue}

My coeditors and I are delighted to share this special issue of the Journal of Obesity focused on understanding the comorbidity between obesity and depression. Depression is highly comorbid with obesity [1-3] and may impede weight loss treatment [4-9]. Just as a successful reduction in the obesity epidemic must entail a multilevel approach to obesity, the papers contained in this special issue represent a diverse examination of the depression and obesity comorbidity. Papers include an examination of individual and environmental factors relevant to depression and obesity, child and adult samples, animal models, and laboratory and epidemiological studies. A brief overview of the papers follows.

Obesity in childhood is highly predictive of adult obesity $[10,11]$. Thus, there has been an increasing focus on the prevention of obesity in children to address the epidemic. Research suggests that in utero factors can contribute to childhood obesity (e.g., [12-14]). Expanding on this work, K. G. Ingstrup and colleagues explored whether symptoms of maternal distress during pregnancy predict childhood obesity at age 7 in a large prospective cohort study in Denmark. Parents are one source of influence discussed in the review article by S. Russell-Mayhew and colleagues regarding mental health issues in childhood obesity. They raise important questions about the challenges overweight and obese children face that can contribute to poorer health outcomes.
In adults, the positive association observed between depression and obesity is relatively robust, though the relationship between suicidal ideation and obesity, particularly in women, is less clear. G. Zhao and colleagues used NHANES data to examine the relationship between suicide and obesity, waist-hip ratio, and waist circumference. Though depression may not necessarily hinder weight loss treatment $[15,16]$, the increased suicidal ideation observed in obese women suggests that depression symptoms should not be ignored during weight loss treatment.

The fact that negative moods can both prompt and result from binge eating episodes, and that binge eating is associated with obesity, suggests that a conversation about depression and obesity would be remiss if it did not include binge eating. R. F. Petersen and colleagues examined the relationship between binge eating disorder, depression, anxiety, and caloric intake in overweight and obese adult women to elucidate how negative mood states impact food intake in the context of binge eating disorder. The work of J. W. Jahng and colleagues provides additional insight into why negative moods may result in binge eating by exploring the dopaminergic activity of rats during fasting and refeeding cycles. These papers nicely set the stage for the study by C. Cifani and colleagues who explored a potential treatment agent for binge eating, Hypericum perforatum, more commonly known as St. John's Wort, in rats.

Lastly, as physical activity may serve as a protective factor for obesity and depression, it is important to understand the barriers and facilitators to engagement in physical activity. 
W. Yang and colleagues explore some of the individual and environmental variables that are associated with engagement in leisure time physical activity. These factors may serve as important treatment targets for interventions that seek to increase physical activity as a potentially parsimonious treatment for comorbid obesity and depression.

Although the articles in this special issue address a range of topics relevant to the depression and obesity comorbidity, there is clearly much more work to be done to reduce the comorbidity. We hope that this special issue stimulates ideas for future research and facilitates interventions for prevention and treatment.
[13] K. E. Rhee, S. Phelan, and J. McCaffery, "Early determinants of obesity: genetic, epigenetic, and in utero influences," International Journal of Pediatrics, vol. 2012, Article ID 463850, 9 pages, 2012.

[14] C. J. Stocker, J. R. S. Arch, and M. A. Cawthorne, "Fetal origins of insulin resistance and obesity," Proceedings of the Nutrition Society, vol. 64, no. 2, pp. 143-151, 2005.

[15] L. Faulconbridge, T. Wadden, R. I. Berkowitz, M. Pulcini, and T. Treadwell, "Treatment of comorbid obesity and major depressive disorder: a prospective pilot study for their combined treatment," Journal of Obesity, vol. 2011, Article ID 870385, 2011.

[16] J. A. Linde, G. E. Simon, E. J. Ludman et al., "A randomized controlled trial of behavioral weight loss treatment versus combined weight loss/depression treatment among women with comorbid obesity and depression," Annals of Behavioral Medicine, vol. 41, no. 1, pp. 119-130, 2011.

\section{References}

[1] E. Atlantis and M. Baker, "Obesity effects on depression: systematic review of epidemiological studies," International Journal of Obesity, vol. 32, no. 6, pp. 881-891, 2008.

[2] B. Blaine, "Does depression cause obesity?: A meta-analysis of longitudinal studies of depression and weight control," Journal of Health Psychology, vol. 13, no. 8, pp. 1190-1197, 2008.

[3] F. S. Luppino, L. M. De Wit, P. F. Bouvy et al., "Overweight, obesity, and depression: a systematic review and meta-analysis of longitudinal studies," Archives of General Psychiatry, vol. 67, no. 3, pp. 220-229, 2010.

[4] M. M. Clark, R. Niaura, T. K. King, and V. Pera, "Depression, smoking, activity level, and health status: Pretreatment predictors of attrition in obesity treatment," Addictive Behaviors, vol. 21, no. 4, pp. 509-513, 1996.

[5] M. de Zwaan, J. Enderle, S. Wagner et al., "Anxiety and depression in bariatric surgery patients: a prospective, followup study using structured clinical interviews," Journal of Affective Disorders, vol. 133, no. 1-2, pp. 61-68, 2011.

[6] T. Legenbauer, M. De Zwaan, A. Benecke, B. Mühlhans, F. Petrak, and S. Herpertz, "Depression and anxiety: their predictive function for weight loss in obese individuals," Obesity Facts, vol. 2, no. 4, pp. 227-234, 2009.

[7] S. Pagoto, J. S. Bodenlos, L. Kantor, M. Gitkind, C. Curtin, and Y. Ma, "Association of major depression and binge eating disorder with weight loss in a clinical setting," Obesity, vol. 15, no. 11, pp. 2557-2559, 2007.

[8] S. M. Somerset, L. Graham, and K. Markwell, "Depression scores predict adherence in a dietary weight loss intervention trial," Clinical Nutrition, vol. 30, no. 5, pp. 593-598, 2011.

[9] G. Pekarik, C. Blodgett, R. G. Evans, and M. Wierzbicki, "Variables related to continuance in a behavioral weight loss program," Addictive Behaviors, vol. 9, no. 4, pp. 413-416, 1984.

[10] M. K. Serdula, D. Ivery, R. J. Coates, D. S. Freedman, D. F. Williamson, and T. Byers, "Do obese children become obese adults? A review of the literature," Preventive Medicine, vol. 22, no. 2, pp. 167-177, 1993.

[11] W. H. Dietz, "Health consequences of obesity in youth: childhood predictors of adult disease," Pediatrics, vol. 101, no. 3, part 2, pp. 518-525, 1998.

[12] E. C. Cottrell and S. E. Ozanne, "Early life programming of obesity and metabolic disease," Physiology and Behavior, vol. 94, no. 1, pp. 17-28, 2008. 


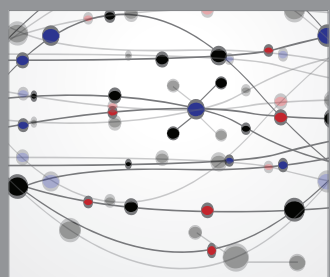

The Scientific World Journal
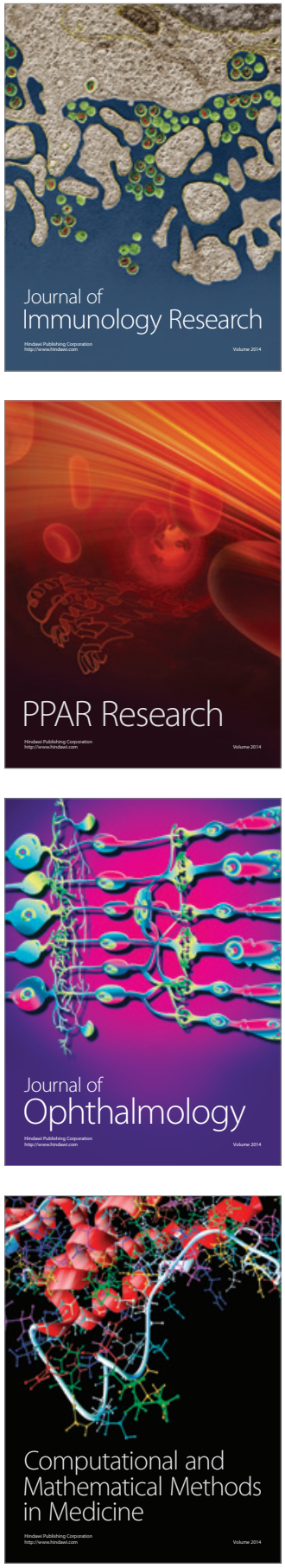

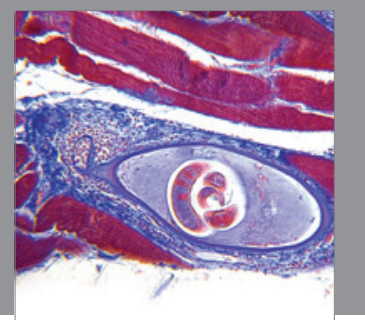

Gastroenterology

Research and Practice
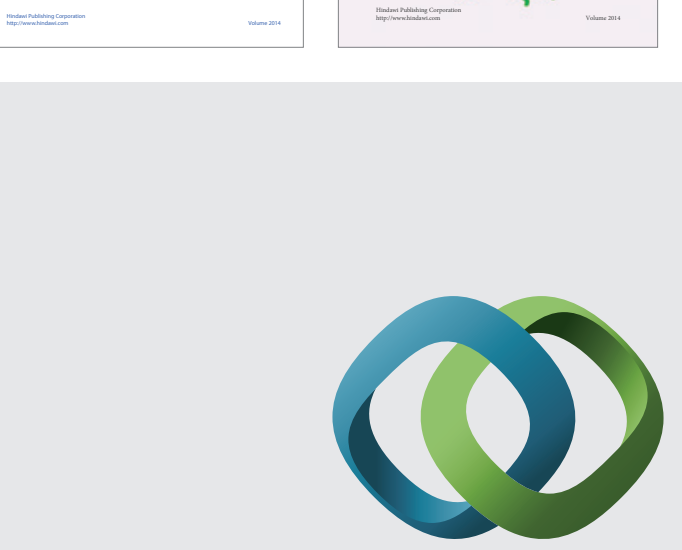

\section{Hindawi}

Submit your manuscripts at

http://www.hindawi.com
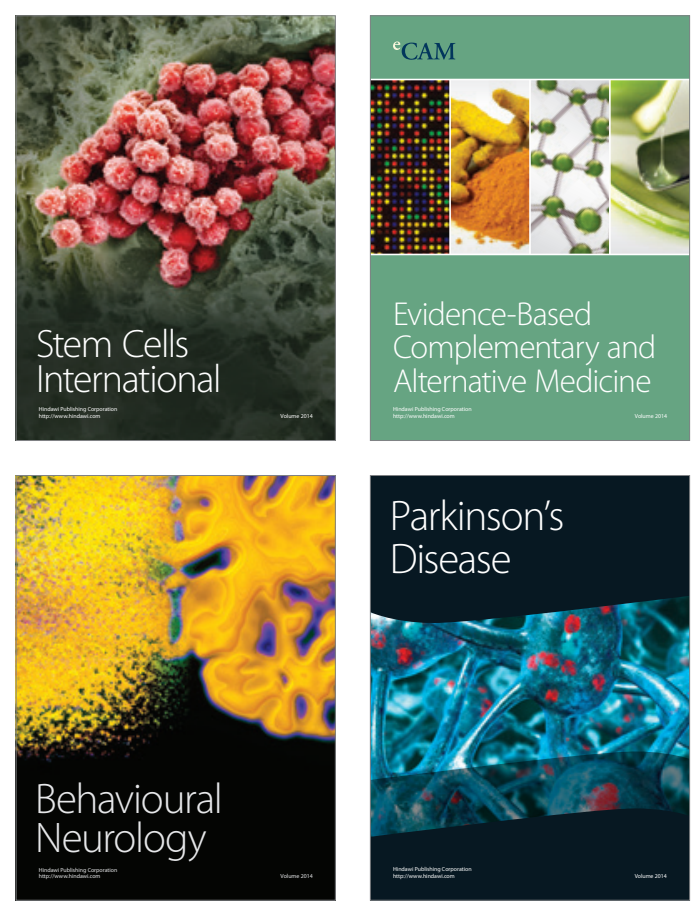

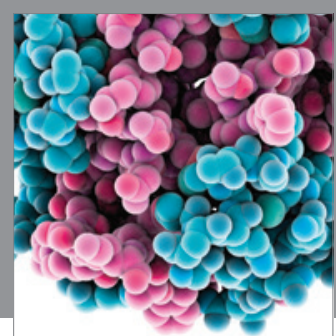

Journal of
Diabetes Research

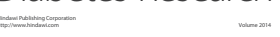

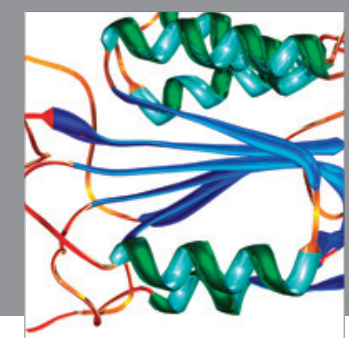

Disease Markers
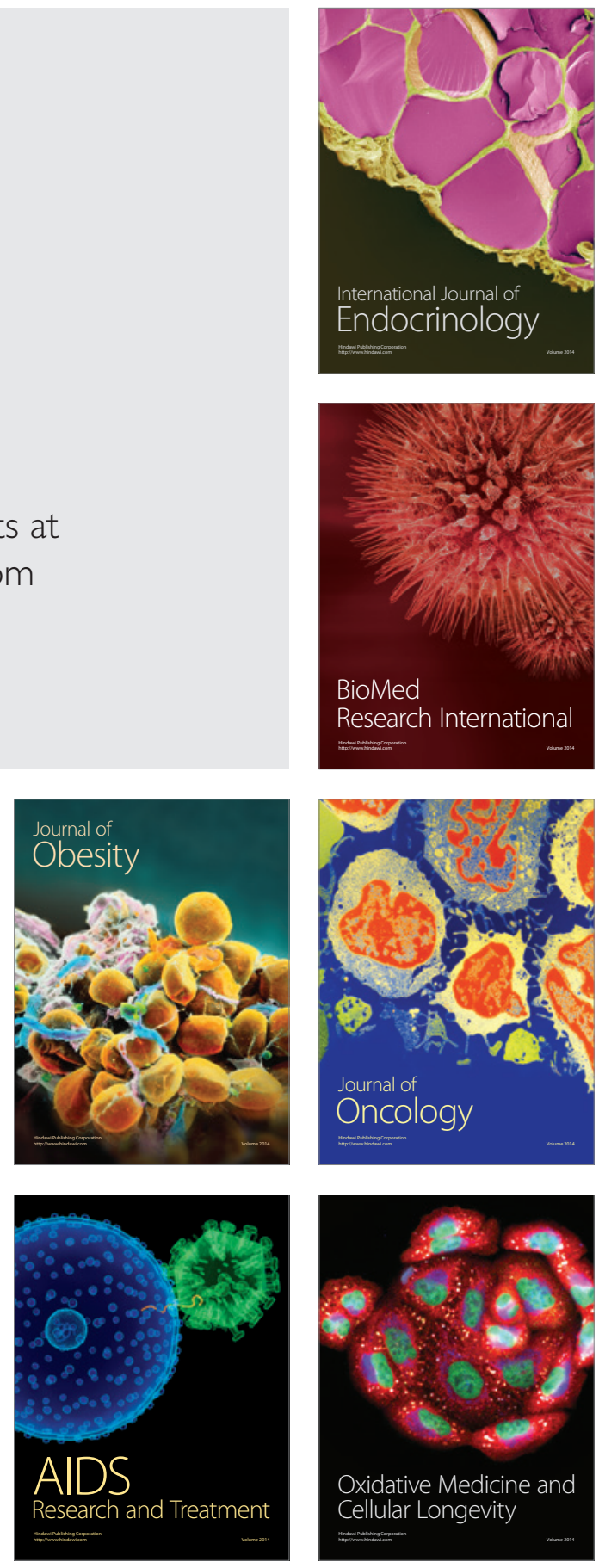